\title{
AVALIAÇÃO DE DOIS BAIRROS EM SANTA MARIA/RS E SEUS PROCESSOS DE DINÂMICA SUPERFICIAL ASSOCIADOS
}

\author{
Amanda ComassettoIensse ${ }^{(a)}$ Luís Eduardo de SouzaRobaina ${ }^{(b)}$ \\ (a) Programa de Pós-Graduação em Geografia, Universidade Federal de Santa Maria, \\ comassettoamanda@gmail.com \\ (b) Departamento de Geociências, Universidade Federal de Santa Maria, lesrobaina@yahoo.com.br
}

EIXO: SISTEMAS GEOMORFOLÓGICOS: ESTRUTURAS, DINÂMICAS E PROCESSOS

\section{Resumo:}

\begin{abstract}
A natureza está submetida e processos naturais de acordo com seu clima,vegetação, solos e tipo de rocha, e dessa forma reage de acordo com a dinâmica dessas variáveis. Quando há uma intervenção antrópica nessa dinâmica, a natureza continuará com seus processos, tentando manter o equilíbrio. Para evitar que desastres naturais ocorram, é necessário planejamento e um estudo aprofundado da área. Muitos eventos não poderão ser evitados, pois estão associados a dinâmica da natureza, porém a ação do homem pode evitar que tragédias aconteçam.
\end{abstract}

Palavras-chaves: Dinâmicas, Processos, Encostas

\section{Introdução}

Partindo do princípio que a paisagem é um sistema aberto com entradas de energias e materiais, torna-se necessário o estudo das variáveis condicionantes para compreender a dinâmica superficial. Existem diversos fatores que implicam na dinâmica superficial das encostas e, dessa forma modificam a paisagem, além de trazer transtornos quando atingem áreas habitadas.

Ao avaliar uma área é importante saber o significado e também a diferença de alguns termos usados para descrever qual a situação local. Os termos mas usados são Susceptibilidade, perigo ou ameaça, vulnerabilidade, risco, evento e desastre.

A natureza está submetida e processos naturais de acordo com seu clima, vegetação, solos e tipo de rocha, e dessa forma reage de acordo com a dinâmica dessas variáveis. Quando há uma intervenção antrópica nessa dinâmica, a natureza continuará com seus processos, tentando manter o equilíbrio.

Para evitar que desastres naturais ocorram, é necessário planejamento e um estudo aprofundado da área. Muitos eventos não poderão ser evitados, pois estão associados a dinâmica da natureza, porém a ação do homem pode evitar que tragédias aconteçam. 
Áreas de risco são cada vez mais ocupadas por pessoas com condições econômicas precárias e poucas tem capacidade de enfrentar um evento. Dessa maneira, torna-se imprescindível a ação do poder público para evitar que essas pessoas sofram com os processos associados aos desastres naturais. É importante salientar que existem várias intervenções que podem ser feitas nas áreas de risco para evitar o desastre.

Os eventosde tornados, terremotos, vulcões, furacões,vendavais, inundações, secas, escorregamentos,erosões entre outros fazem parte da dinâmica natural doPlaneta, ou seja, vai ocorrer com ou sem a presença do homem e recebem a denominação de processosnaturais. Quando os processos naturais ocorrem em áreasdensamente ocupadas, principalmente na área urbana e ocupada por população de baixa renda, podem trazer consequênciaseconômicas e sociais de significativa dimensão.Nestes casos, tais acontecimentos são chamados dedesastres naturais.

O risco é a probabilidade de perda que é esperada para uma área habitada em um determinado tempo, devido à presençaiminente de um perigo (UNDP, 2004). Dessa forma, Cerri; Amaral (1998) colocam que os fenômenos de origem geologica-geomorfológica, pode ou não gerar perdas e danos. Cerri; Amaral (op. cit, 1998) também colocam a cerca da susceptibilidade a característica da possibilidade de ocorrência de um evento.

Rodríguez (2000) afirma que a vulnerabilidade está relacionada às desvantagens sociais que são reflexos e produtos da pobreza, que, por suavez, é entendida como condição social que afeta de maneira restritiva indivíduos, grupos sociais elugares. Marandola Jr.; Hogan (2004) salientam que para entender as complexas relações entre o risco, o perigo, a vulnerabilidade e a resiliência é necessário discutir as relações deestabilidade e desestabilidade, que nem sempre são delimitadas claramente, e não seguem regras matemáticas ou geométricas simples. Portanto, é necessário buscar novas perspectivase abordagens para compor um quadro analítico mais amplo e que possibilite a compreensão plena dos conceitos mencionados e de como as pessoas os enfrentam. (CUNICO, OKA-FIORI, 2014).

Dito isto, o objetivo desse relatório é foi uma avaliação das áreas visitadas nos trabalhos de campo dos dias 04 de maio de 2016 no Bairro Itararé e no dia 25 de maio de 2016 no Bairro Nova Santa Marta, em Santa Maria/RS identificando os processos de dinâmica superficial associados em cada local. 


\section{Metodologia}

A partir das aulas expositivas tratadas na disciplina de Processos De Dinâmica Superficial E Riscos Naturais Associados (GCC924), buscou-se o aprofundamento sobre os processos e dinâmicas naturais que ocorrem nas áreas de risco.

Posteriormente, foram feitas duas saídas de campo a fim de observar os processos in loco. $\mathrm{O}$ primeiro campo foi na encosta do Morro do Cechella, no bairro Itararé, onde foram observadas algumas dinâmicas de encostas presentes. O segundo campo, foi no bairro Nova Santa Marta, onde foram observadas algumas dinâmicas erosivas.

Por último foi feito o presente relatório, a partir das observação e anotações nos dois trabalhos de campos. Os mapas foram construídos em SIG ArcGIS 10.2.2 e também foram utilizadas imagens do GoogleEarth.

\section{Breve caracterização geográfica da área de estudo}

Santa Maria encontra-se no centro geográfico do estado do Rio Grande do Sul entre o rebordo do Planalto sul-rio-grandense e a Depressão Periférica, a $29^{\circ} 41^{\prime} 25^{\prime}$ ' de latitude sul e $53^{\circ} 48^{\prime}$ 42" de longitude oeste.Totalizando uma população total, segundo o IBGE (2010), de 261.403 habitantes, sendo que aproximadamente $95 \%$ de sua população reside na área urbana.Destacase também como polo regional, caracterizada pela prestação de serviços educacionais, de saúde, comercial e militar.

A figura 1 mostra a área urbana de Santa Maria e os dois bairros visitados durante os trabalhos de campo da disciplina. 


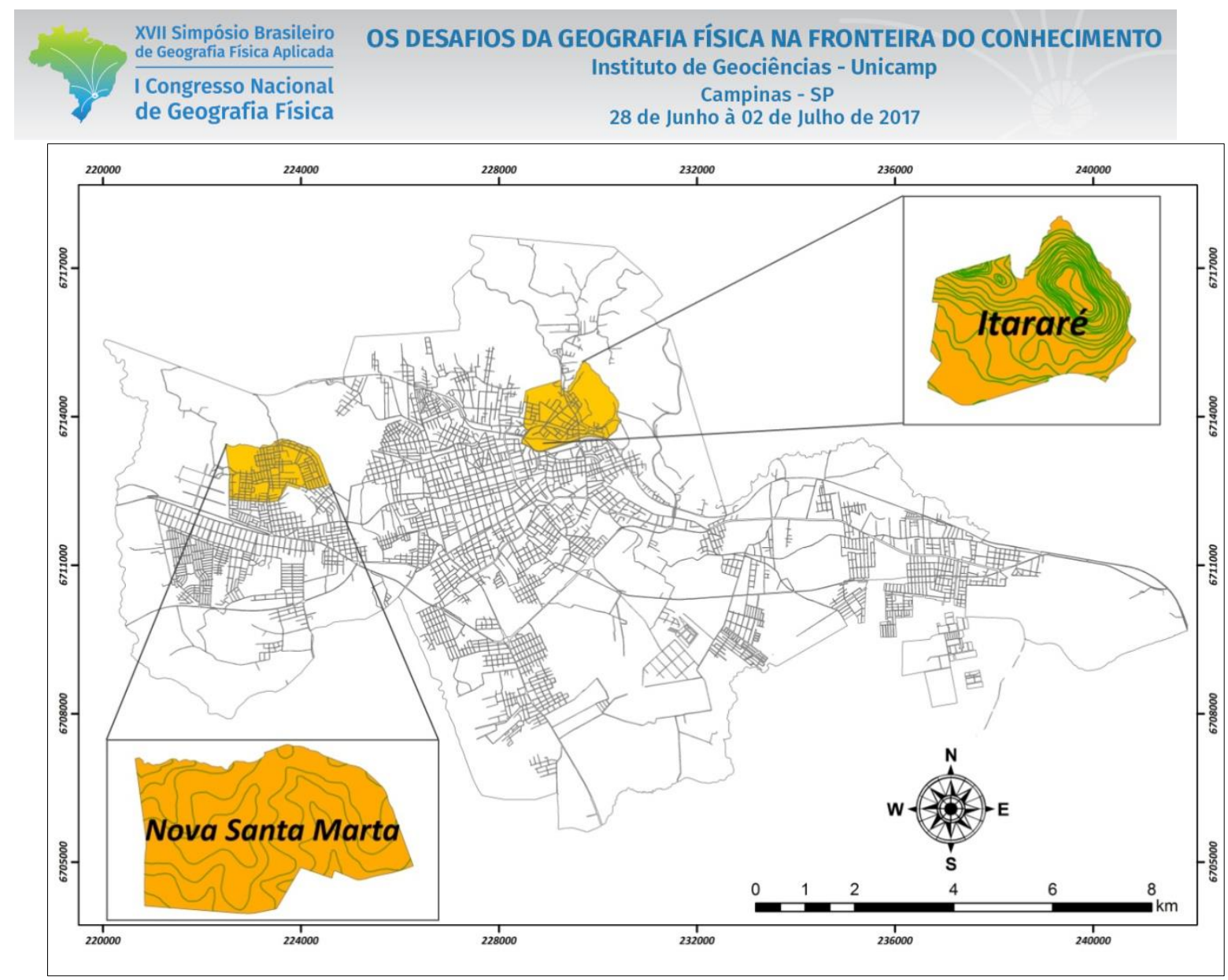

Figura 1- Área Urbana de Santa Maria com a localização dos bairros visitados durante os trabalhos de campo.Org.: Amanda ComassettoIensse

\subsection{Trabalho de campo 04 de maio de 2016}

O primeiro trabalho de campo, foi realizado no dia 04 de maio de 2016, no bairro Itararé, nas encostas do Morro Cechella (Figura 2).

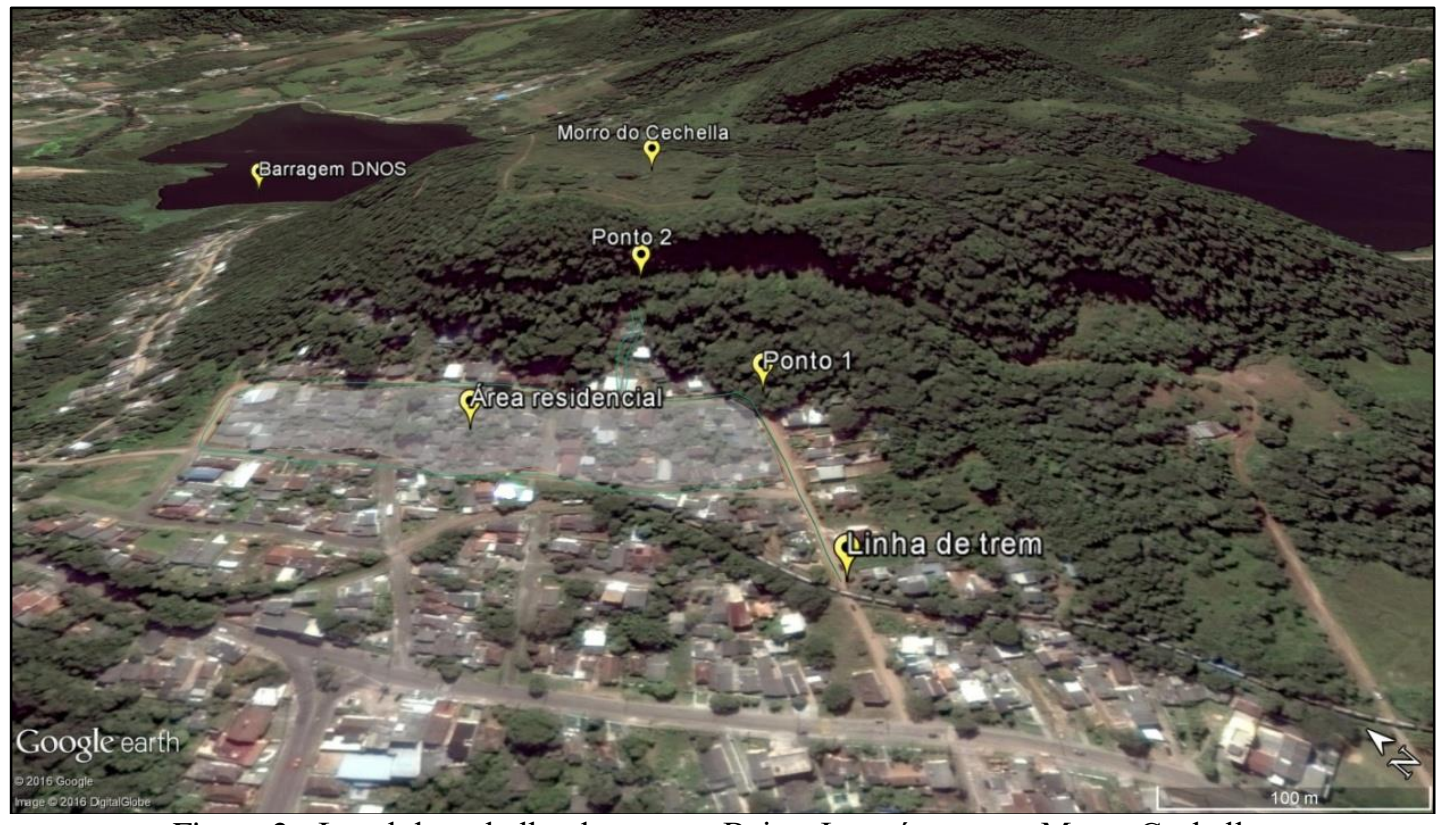

Figura 2 - Local do trabalho de campo, Bairro Itararé, encosta Morro Cechella. 


$\begin{aligned} & \text { XVII Simpósio Brasileiro } \\ & \text { de Geografia Fisica Aplicada }\end{aligned}$
$\begin{aligned} & \text { I Congresso Nacional } \\ & \text { de Geografia Fisica }\end{aligned}$

O local visitado é composto por rochas sedimentares (ARENITO) com pedreira a cima. Esse tipo de substrato facilita o escorregamento, apesar da erosão ocorrer de acordo com o fluxo e intensidade das chuvas. A vegetação presente ao longo da encosta que possui as áreas ocupadas é elemento importante para evitar a erosão.

Algumas árvores observadas ao longo das ocupações na encosta estão susceptíveis ao efeito alavanca que de acordo com Gray e Leiser (1982) atribuem como efeitos desfavoráveis: O efeito alavanca é uma força cisalhante transmitida pelos troncos das árvores ao terreno, quando suas copas são atingidas por ventos. A figura 3 mostra uma árvore com potencial efeito alavanca, muito próxima a uma residência.

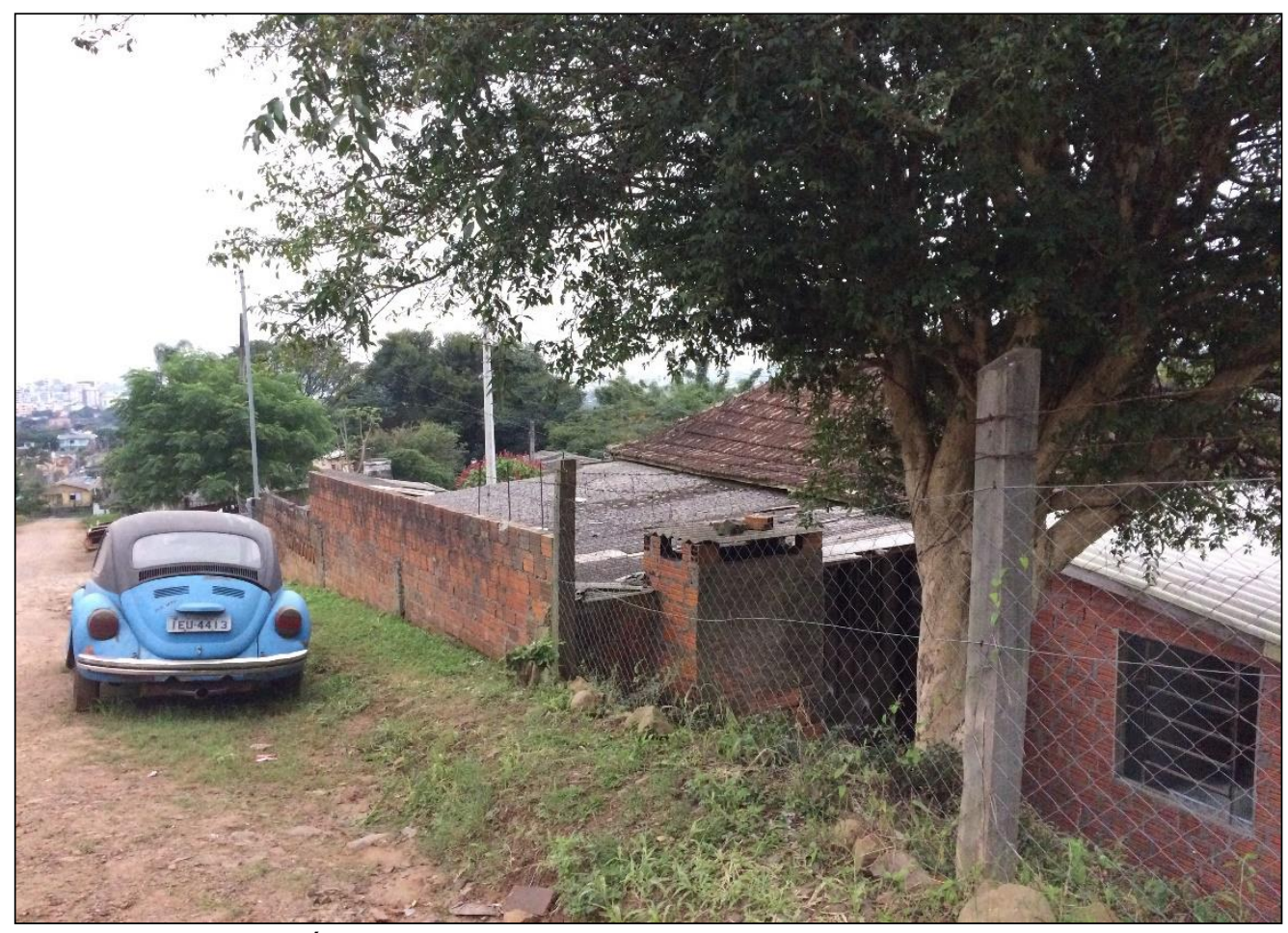

Figura 3 - Árvore próxima a residência com potencial para efeito alavanca.

Fonte: Acervo Pessoal

Ao longo do trajeto foi possível observar muitos resíduos lançados junto a encosta (figura 4), indicando grande susceptibilidade de ocorrência de processos superficiais atingindo as ocupações. 


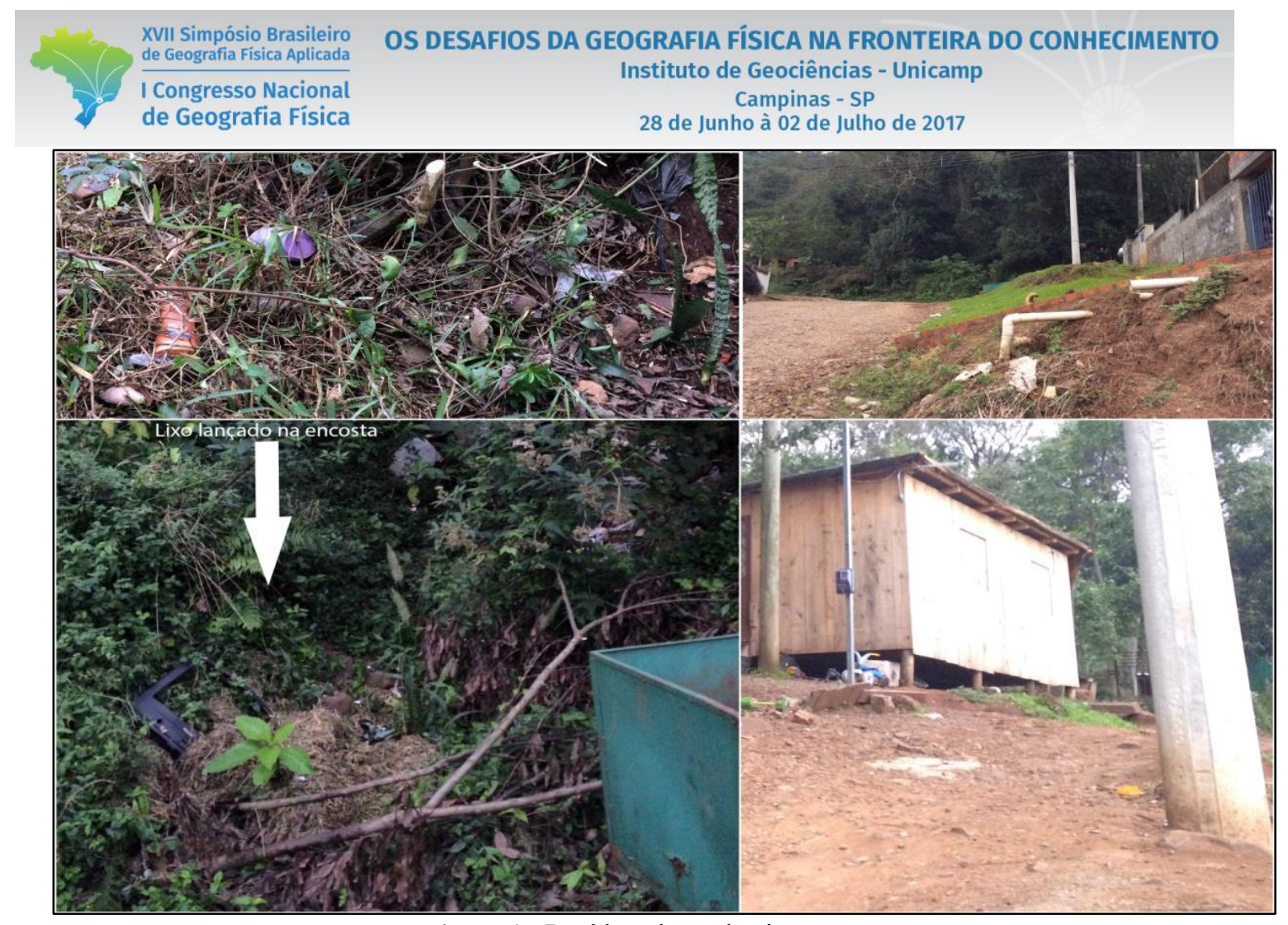

Figura 4 - Resíduos lançados junto a encosta.

Fonte: Acervo Pessoal

É importante salientar os fatores condicionantes aos processos, sendo os mais importantes:

Litologia, depósitos superficiais, solos, relevo, clima, vegetação e ações antrópicas. A encosta é formada por rocha sedimentar, sendo o Arenito de origem fluvial da formação caturrita, sendo mais susceptível a erosão do que escorregamento. Também foi possível observar na subida do morro vegetação de brejo sombrio, com muita umidade. A figura 5 mostra um esquema da área próxima ao Cechella.

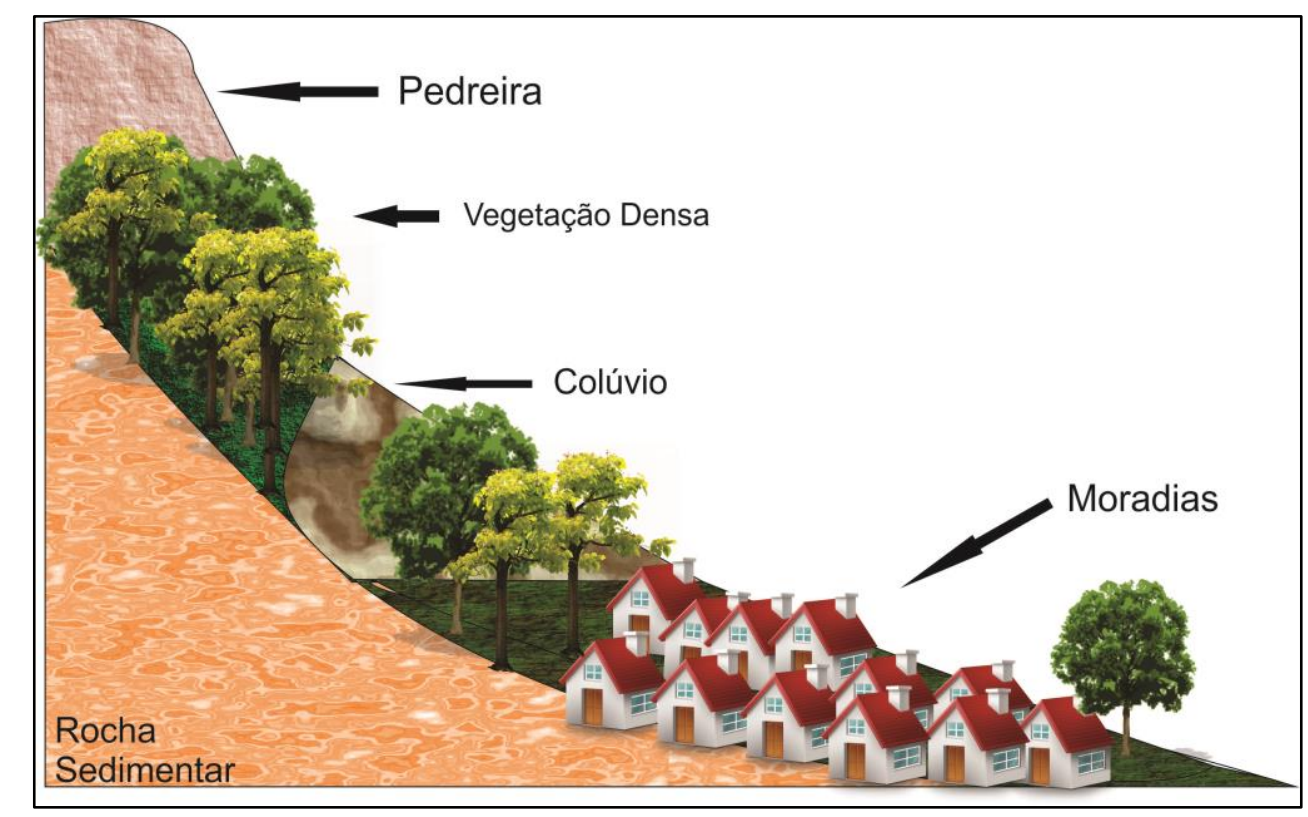




$\begin{aligned} & \text { XVII Simpósio Brasileiro } \\ & \text { de Geografia Fisica Aplicada }\end{aligned}$
$\begin{aligned} & \text { I Congresso Nacional } \\ & \text { de Geografia Física }\end{aligned}$$\quad \begin{gathered}\text { OS DESAFIOS DA GEOGRAFIA FISICA NA FRONTEIRA DO CONHECIMENTO } \\ \text { Instituto de Geociências - Unicamp } \\ \text { Campinas - SP }\end{gathered}$

Figura 5 - Esquema da área próxima ao Cechella.Org.: Iensse, A.C.

Apesar da vegetação de grande porte associada a vegetação de pequeno porte na encosta do morro, proteger da erosão, ao mesmo tempo torna-se um perigo para as residências. Também foi observado espaços vazios facilitando o trabalho da drenagem na encosta, além de situações localizadas de cortes.

A área da encosta do Cechella no Bairro Itararé possui muitas residências que podem sofrer com algum evento natural que possa vir ocorrer. Foi consenso durante o trabalho de campo que cada residência deveria ser avaliada isoladamente, pois precisam de intervenções diferentes ao longo da encosta.

Por se tratar de uma área de interesse social, fica mais difícil intervir no local. Além da questão burocrática, também é necessária vontade política.

\subsection{Trabalho de campo 25 de maio de 2016}

O segundo trabalho de campo, foi realizado no dia 25 de maio de 2016, no bairro Nova Santa Marta (Figura 6).

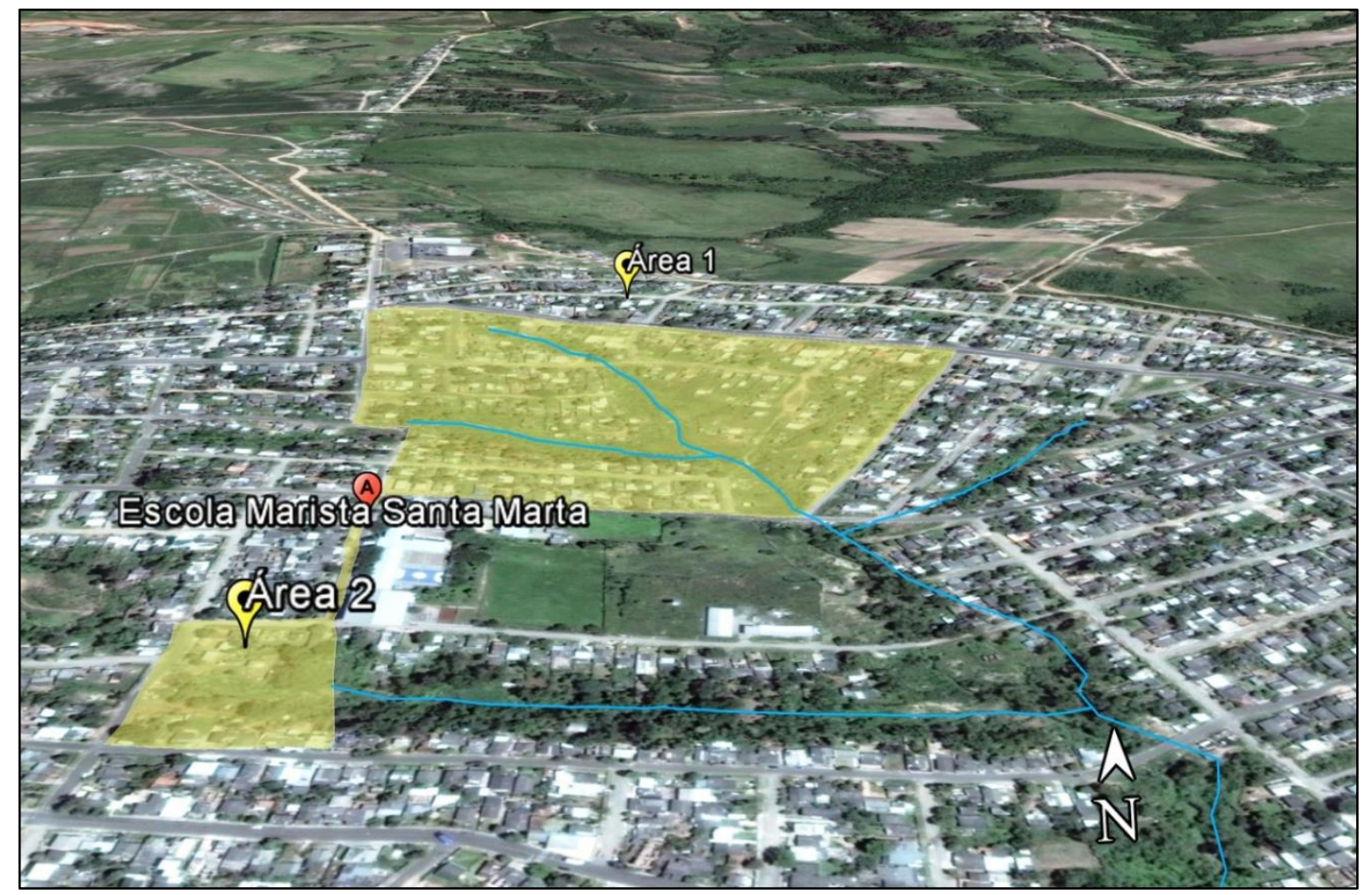

Figura 6 - Trabalho de campo do dia 25 de maio de 2016, Nova Santa Marta. Org.: Iensse, A.C. 


$\begin{gathered}\text { XVII Simpósio Brasileiro } \\ \text { de Geografia Fisica Aplicada }\end{gathered}$
$\begin{aligned} & \text { I Congresso Nacional } \\ & \text { de Geografia Física }\end{aligned}$

A área visitada no dia 25 de maio de 2016, pertence ao Nova Bairro Santa Marta, que na década de 80 era uma fazenda de gado a qual foi desapropriada para construção de um conjunto habitacional. Não sendo realizado o projeto de habitação, a partir da década de 90 a fazenda foi ocupada desordenadamente por pessoas de baixa renda, e popularmente conhecida como "sem-teto"Silva (2003).É um dos locais mais socialmente deprimido do município de Santa Maria e tem importante atuação de tráfico de drogas.

A Nova Santa Marta possui substrato de Arenito em contato com Lamito, dessa forma possuindo diferentes permeabilidades. O bairro também é importante pelo fato de possuir cabeceiras de drenagem, pertencentes ao Arroio Caderna, parte da drenagem é ilustrada em azul na figura 6. Por se tratar de substrato de Arenito, o bairro possui um solo bem arenoso, e o contato entre Arenito e Lamitoé importante para a erosão subterrânea causando solapamento.

Ao longo da percurso feito durante o trabalho de campo, foi possível notar as ocupações avançando para o canal do Arroio Cadena (Figura 7). Essas ocupações irregulares alteram a paisagem local causando efeitos negativos na bacia hidrográfica, além de representar perigo aos moradores devido aos processos que possam vir ocorrer.

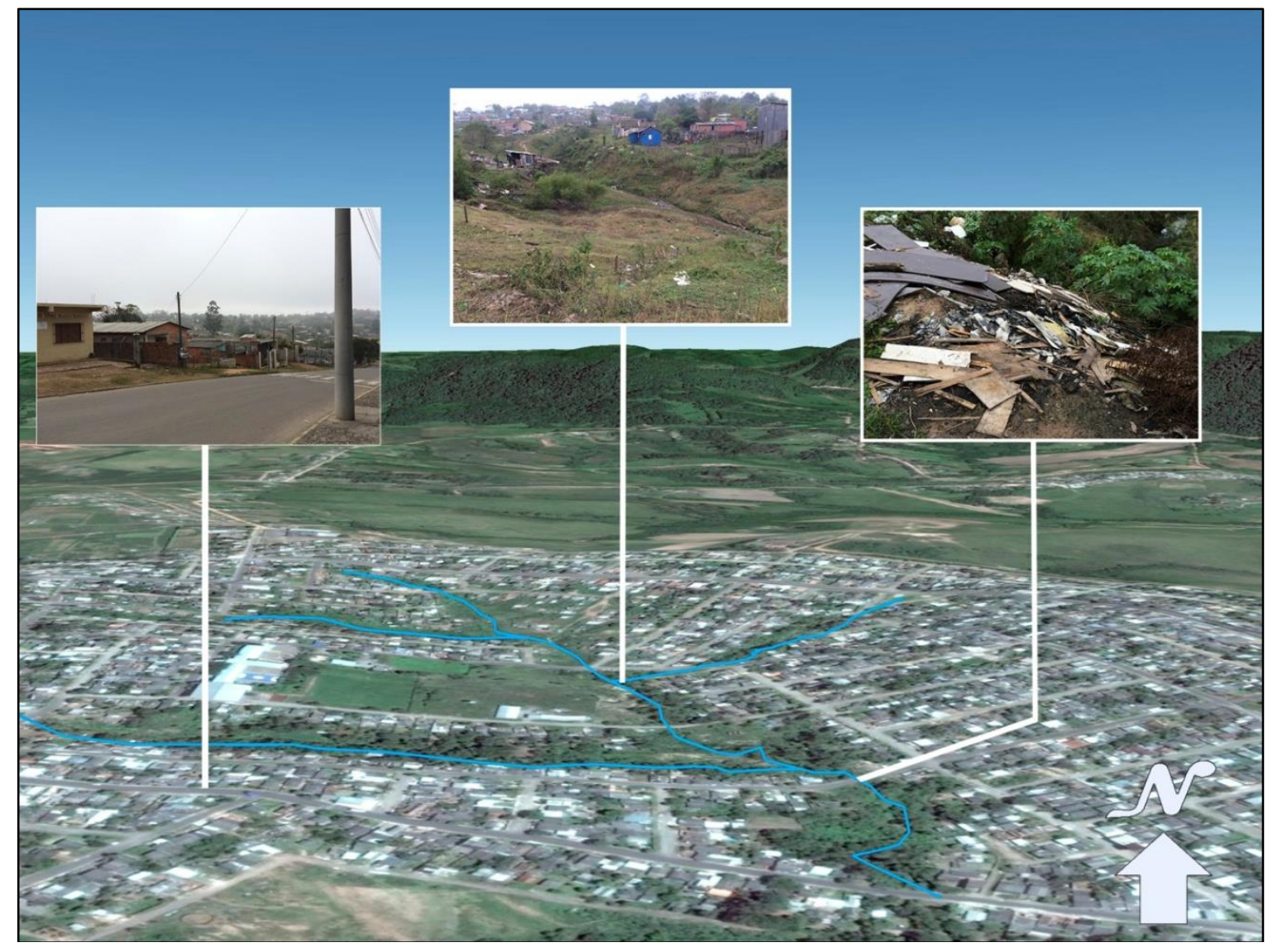


Figura 7 - Residências observadas junto as margens do canal do Arroio Cadena.

A área da Nova Santa Marta é um região úmida de muita água servida. Além de possuir cabeceiras de drenagens do Arroio Cadena, o bairro fica no divisor de águas do Arroio Cadena e Arroio Ferreira, de acordo com a Figura 8.

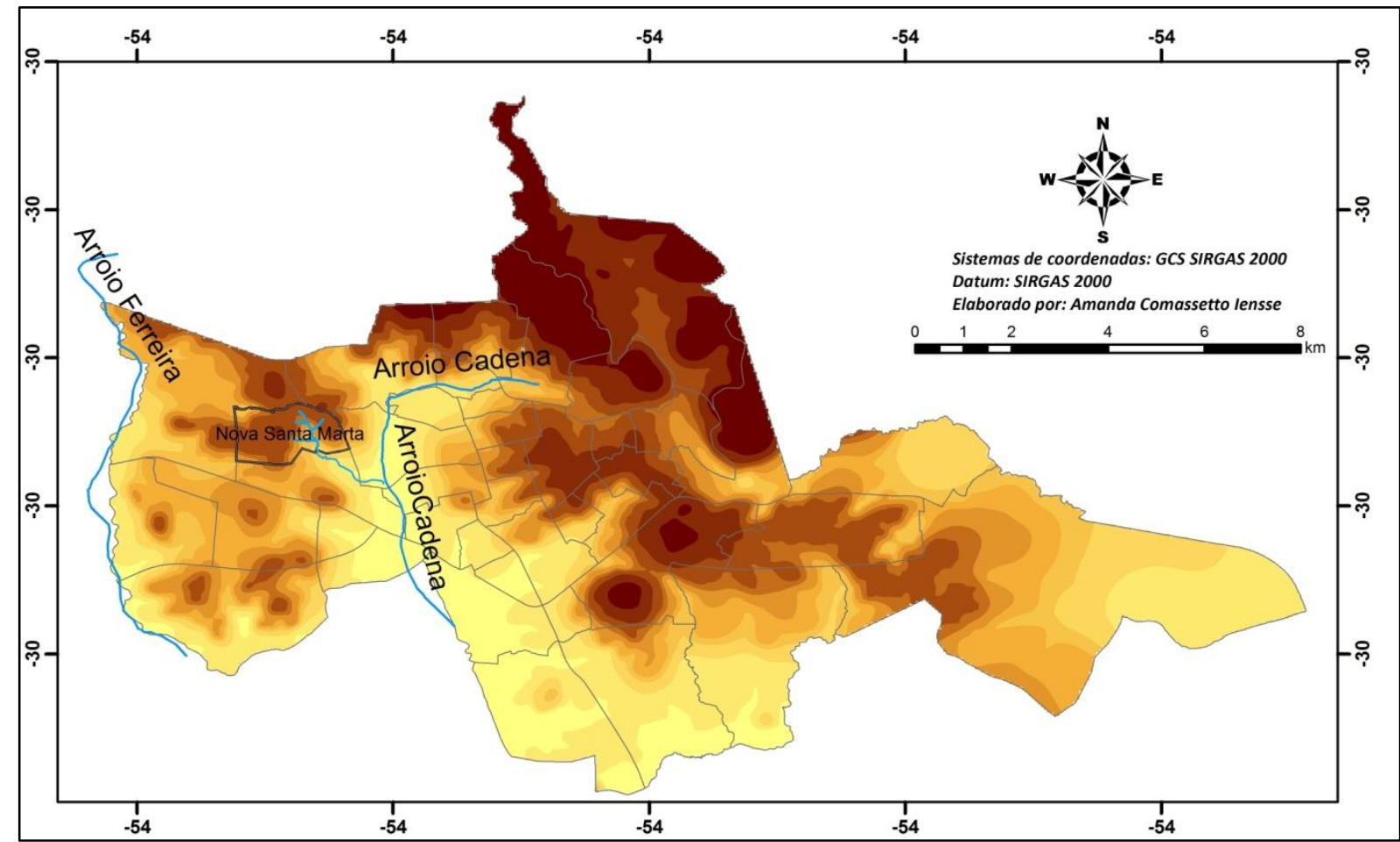

Figura 8 - Mapa de localização do Bairro Nova Santa Marta, divisor de águas do Arroio Cadena e Arroio Ferreira.Org.: Iensse, A.C.

É também observado muito descartes irregular de lixo no Bairro Nova Santa Marta. O lixo é jogado ao longo dos canais e também do divisor de águas, mudando o regime do escoamento superficial e poluindo tanto Arroio Cadena quanto o Arroio Ferreira. A figura 9 mostram alguns locais e tipos de lixos descartados no Bairro. 


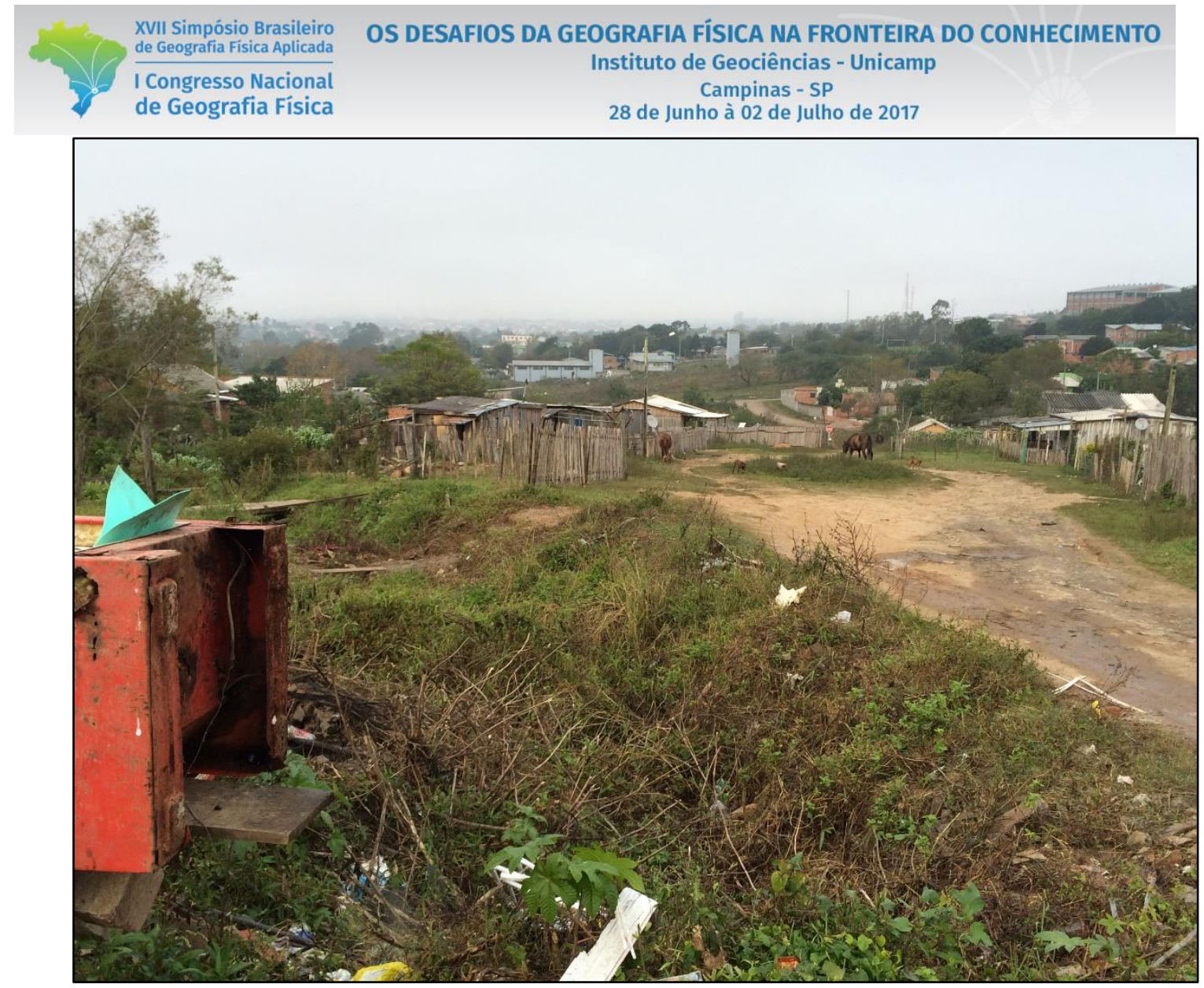

Figura9 -Descartedelixo nos canais de drenagem do BairroNovaSantaMarta

\section{Considerações Finais}

Após os trabalhos de campo nas encostas do Morro Cechella no Bairro Itararé e na Nova Santa Marta, foi possível identificar alguns processos que causam diferentes impactos na população que vive nesses locais. O adensamento populacional nas cidades e a segregação da população de baixa renda, faz com que haja ocupação irregular e desordenadas nas áreas de maior fragilidade ambiental da cidade.

As encostas visitadas no Morro Cechella evidenciam uma ocupação complexa e difícil de avaliar sem um estudo detalhado da área. Foi consenso em campo que cada moradia deveria ser avaliada individualmente pois no mesmo local, haviam interferências diferenciadas na encosta. A moradias foram construídas sobre colúvio, tornando-as muito instáveis e susceptíveis a processos de escorregamentos, mesmo de pequeno porte, dependendo da intensidade das chuvas.

Já na área que se localiza o Bairro Nova Santa Marta, onde encontram-se as cabeceiras de drenagens do Arroio Cadena, foi possível identificar as ocupações avançando para os canais de drenagem. Também foi possível identificar talude íngreme com degraus erosivos típicos. 
Os canais de drenagens possuem muito descartes irregulares de lixo, causando erosões de margens e assoreamento.

Tendo em vista os aspectos apresentados, torna-se evidente a urgência de políticas públicas voltadas para a minimização dos riscos associados às ocupações irregulares nas encostas do Cechella e também no bairro Nova Santa Marta. É imprescindível também a conscientização ambiental da população que reside nesses locais, pois a intervenção desordenada seja em encostas ou canais de drenagens destrói o meio ambiente e causa risco para a sua população.

\section{Referências}

CERRI, L. E. S. \& Amaral, C. P. Riscos Geológicos. In: OLIVEIRA, A. M. S. \& BRITO, S. N. A. (eds.) 1998.

CUNICO, C. OKA-FIORI, C. O ESTADO DE NORMALIDADE E O ESTADO DE EXCEÇÃO DIANTE DA IMPORTÂNCIA DAS CATEGORIAS DE "VULNERABILIDADE", "RISCO" E "RESILIÊNCIA" In: CAMINHOS DE GEOGRAFIA: Uberlândia. 2014

GRAY, G.L.; LEISER, A.J. Role of vegetation in stabilityandprotection of slopes. In:Biotecnicalslopeprotectionanderosioncontrol. P.37-65. New York. Van NortrandReinholCompany, 1982.

INSTITUTO BRASILEIRO DE GEOGRAFIA E ESTATÍSTICA (IBGE).Censo demográfico de 2010.Disponível em: http://www.sidra.ibge.gov.br/bda/tabela/listabl.asp?z=t\&c=1552

MARANDOLA JR., E.; HOGAN, D. J. O risco em perspectiva: tendências e abordagens. In: Geosul. v. 19, n. 38. Florianópolis, 2004.

RODRÍGUEZ, J. Vulnerabilidad demográfica: una faceta de lasdesventajassociales. Santiago del Chile: CEPAL (Serie Población y Desarrollo), 2000.

SILVA, J. B. Estatuto da cidade versus estatuto de cidade - Eis aquestão. In: CARLOS, Ana Fani Alessandri; GERAIGES, Amália Inês (orgs.).Dilemas urbanos: novas abordagens sobre a cidade. São Paulo: Contexto, 2003.

UNDP SustainableDevelopment Networking Programme, Report of anindependentexternal assessment. 2004. 